\title{
Investigation of marital satisfaction and its relationship with job stress and general health of nurses in Qazvin, Iran
}

\author{
Jalil Azimian ${ }^{1}$, Pegah Piran², Hassan Jahanihashemi ${ }^{3}$, Leila Dehghankar ${ }^{4}$
}

${ }^{1}$ Ph.D. of Nursing, Assistant Professor, Department of Nursing, Member of Social Determinants of Health Research Center, Qazvin University of Medical Sciences, Qazvin, Iran

${ }^{2}$ M.Sc. in Nursing Education, Lecturer, Department of Nursing, Faculty of Nursing and Midwifery, Hormozgan University of Medical Sciences, Bandar Abbas, Iran

${ }^{3}$ Ph.D. of Biostatistics, Associate Professor, Children Growth Research Center, Qazvin University of Medical Sciences, Qazvin, Iran

${ }^{4}$ M.Sc. in Nursing Education, Lecturer, Department of Community Health Nursing, Faculty of Nursing \& Midwifery, Qazvin University of Medical Sciences, Qazvin, Iran

\section{Type of article: Original}

\begin{abstract}
Background: Pressures in nursing can affect family life and marital problems, disrupt common social problems, increase work-family conflicts and endanger people's general health.

Aim: To determine marital satisfaction and its relationship with job stress and general health of nurses.

Methods: This descriptive and cross-sectional study was done in 2015 in medical educational centers of Qazvin by using an ENRICH marital satisfaction scale and General Health and Job Stress questionnaires completed by 123 nurses. Analysis was done by SPSS version 19 using descriptive and analytical statistics (Pearson correlation, t-test, ANOVA, Chi-square, regression line, multiple regression analysis).

Results: The findings showed that $64.4 \%$ of nurses had marital satisfaction. There was significant relationship between age $(\mathrm{p}=0.03)$, job experience $(\mathrm{p}=0.01)$, age of spouse $(\mathrm{p}=0.01)$ and marital satisfaction. The results showed that there was a significant relationship between marital satisfaction and general health $(\mathrm{p}<0.0001)$. Multiple regression analysis showed that there was a significant relationship between depression $(\mathrm{p}=0.012)$ and anxiety ( $\mathrm{p}=0.001$ ) with marital satisfaction.

Conclusions; Due to high levels of job stress and disorder in general health of nurses and low marital satisfaction by running health promotion programs and paying attention to its dimensions can help work and family health of nurses.
\end{abstract}

Keywords: Health, Depression, Satisfaction, Stress

\section{Introduction}

Work is one of the main sources of stress in people (1). If there is stress in the workplace and it is related to workplace factors, this issue shows job stress (2), and it occurs when job requirements are not matched with skills, supportive resources, and needs of employers $(3,4)$. About $30 \%$ of labor forces in developed countries are experiencing job stress (5). Nursing is known as a job with high risk of exhaustion and disease. The hospital environment can cause stress and physical problems among its employees (6). In fact, job stress can lead to physical injury or mental illness, and in the long term, can cause negative results in performance of people and ultimately, in its organization (7). Various factors affect job stress of nurses including working in closed environments, changing shifts, role conflict, job dissatisfaction, fear of job loss, exposure to death and suffering of patients, and unknown professional responsibilities $(4,8,9)$. In the meantime, employment status of people plays an important role in their satisfaction of marital life (1). Work-related stresses probably lead to dissatisfaction with job roles and this issue

\section{Corresponding author:}

Leila Dehghankar, Department of Community Health Nursing, Faculty of Nursing \& Midwifery, Qazvin University of Medical Sciences, Qazvin, Iran. Tel: +98.2833336001, Fax:+98.2833338034, Email: Dehghan247@gmail.com Received: December 06, 2016, Accepted: February 20, 2017, Published: April 2017 iThenticate screening: February 08, 2017, English editing: April 18, 2017, Quality control: April 20, 2017 (C) 2017 The Authors. This is an open access article under the terms of the Creative Commons Attribution-NonCommercialNoDerivs License, which permits use and distribution in any medium, provided the original work is properly cited, the use is non-commercial and no modifications or adaptations are made. 
reduces total life satisfaction (10). Marital satisfaction over time, is connected with multiple individual, family, and occupational factors such as shifts, work experience, and work location (11). When couples have marital satisfaction, family strength is good and they can deal with problems properly and be protected from damages (12). Landa showed that by increasing employment pressure, marital dissatisfaction would also be increased (13). Burke and Weir quoted by Owusu found that proper marriage can lead to prevention of job stress and increase of marital satisfaction (14). The results indicated that the married people whose lives are stable and have enough marital satisfaction, generally have long lives; more likely survive cancer; have healthy and desirable eating and suffer less from disease, depression, and psychological problems (15). Lushington and Dawson showed, according to the nurses' expressions, shift work has negative consequences on family and social issues and disrupts social activities shared with spouses, which significantly endangers their general health and therefore, shift work to them is a great source of job and family conflict $(16,17)$. Lambert, citing from Shahraki Vahed stated that from his 130 studied jobs, nurses gained rank 27 in referring to the doctor for problems caused by lack of general health (18). The effect of psychological conditions of work on one's mental disorders and its recovery is indicating (19). Having general health in nurses is important because it leads to professional solidarity and cohesion provided in the shadow of psychological balance (18). Overload, severe shortage of time, stress, and tension caused by work are linked with mild mental disorders (20). Identifying and resolving the underlying causes, creating and maintaining emotional, behavioral, physical, and psychological reactions in nurses are considered as a necessity (21). Given that marital satisfaction has an effect on individual health, and stressors in the work environment endanger human health, nurses are faced with various stressors in the workplace to achieve goals of ensuring the health and welfare of patients and also in the home environment, due to a multiplicity of roles which are irrefutable responsibilities; therefore, because of being busy by working, directly or indirectly are exposed to physical and psychological damage and are susceptible to work-family conflicts. Pressures in the nursing profession can affect family life and marital issues, and cause sexual problems, disintegration of social common issues, and increase work-family conflicts and endanger their general health (22). Nowadays, job stress is known as one of the most important pests of organizations, which on one hand affects people's health of body and mind and on the other hand leads people to negative consequences of marital satisfaction (1). Several studies have been conducted in the province or other parts of the country but the passage of time and advancement of today's world with all its stress should not be ignored, and by taking into account the fact that most workers in the nursing profession are women and in our society women have always had a huge part of family responsibilities in marital life, the nursing job, due to the specific nature, extreme stress, and workflow involves separation of women from the center of the family. Therefore, the study aimed to determine the amount of marital satisfaction and its relationship with job stress and general health in married nurses.

\section{Material and Methods}

\subsection{Research Design and Participants}

This descriptive and cross-sectional study was conducted on 123 nurses working in teaching hospitals in Qazvin via stratified random sampling method. In each hospital, there is one floor, and six teaching hospitals of Qazvin were selected and from each floor containing several departments based on the ratio, nurses were selected randomly.

\subsection{Research Tools}

Research tools to collect data in this research included a questionnaire containing demographic data (age, gender, education level, work experience, number of children, shift work, marriage age, age of spouse, work place, type of employment), General Health Questionnaire (GHQ-28), Nurse's Job Stress (NSS), and ENRICH Marital Satisfaction.

\subsubsection{Job Stress Questionnaire of Nurses}

To investigate job stress among nurses, the scale of nursing stress prepared by Gray Toft and Anderson was used (23). It contains 34 phrases that are in 7 areas in relation to job stress factors including: death and dying of patient (7 phrases), conflict with physicians (5 phrases), inadequate preparation ( 3 phrases), lack of support ( 3 phrases), conflict with other nurses (5 phrases), workload (6 phrases), and uncertainty regarding treatment (5 phrases). This tool, based on the Likert Scale, has been measured as; is not stressful never (1 points) to always is stressful (4 points). Total scores range from 34-136 with a score less than or equal to 68 is low stress, $69-103$ is moderate stress, and greater or equal to 104 is classified high in stress (2). Validity and reliability of the questionnaire has been confirmed in numerous studies in Iran $(1,24,25,26)$.

\subsubsection{ENRICH Marital Satisfaction Questionnaire}

The ENRICH Marital Satisfaction Questionnaire was used as a valid research tool in various clinical practices. This questionnaire was designed in America for use of researchers and therapists of marital issues and in 1989, was reevaluated for validity and reliability $(27,28)$. The Enrich Inventory questionnaire has 12 subscales (Idealistic 
distortion, marital satisfaction, personality issues, communication, conflict resolution, financial management, leisure activities, sexual relation, children and parenting, family and friends, equalitarian roles, and religious orientation). Each question of Enrich Inventory subscales is scored based on a five-point Likert scale. The questionnaire included 47 questions totally, which some of the questions are scored directly and others inversely and to each, an option score of 1 to 5 is given. Calculated scores for norm scale is t-score where the mean is equal to 50 and SD is 10 and if the obtained score is less than 30 , it indicates severe dissatisfaction with the marital relationship among spouses. A score between 30 and 40 indicates dissatisfaction with the marital relationship. A score between 40 and 60 indicates relative and moderate marital satisfaction with the marital relationship among spouses, a score between 60 and 70 indicates high satisfaction with the marital relationship, and scores above 70 indicate wonderful marital satisfaction. The validity and reliability of these instruments have already been reviewed and approved $(28,29)$.

\subsubsection{General Health Questionnaire}

This questionnaire is provided by Goldberg and Hillier (30) and has four subscales and each scale has seven questions. The scales are: somatic symptoms (items 1-7); anxiety/insomnia (items 8-14); social dysfunction (items 15-21); and severe depression items (22-28). In each scale from score 6 and totally from score 22 to more indicated symptoms (2). This tool is also used in many researches and its validity and reliability have been approved $(1,31$, $32)$.

\subsection{Research Ethics}

After receiving permission to research from the Research Ethics Committee (license number: IR.QUMS.REC.1394.7) of Qazvin University of Medical Sciences, ensuring the confidentiality of information, and after obtaining informed consent from eligible individuals by the researcher, the questionnaires were completed. The sample size using standard deviation 13 from the study of Barzideh et al. (33) and confidence level of $95 \%$ and statistical power of $80 \%$ was estimated equal to 125 people.

\subsection{Statistical Analysis}

After entering data in SPSS software version 19 the analysis was done by using descriptive and inferential statistical methods (Pearson's correlation coefficient, independent t-test, ANOVA, Chi-square test, and regression).

\section{Results}

The results showed that mean and standard deviation of subjects' age were $86.5 \pm 36.32$ years, most of the subjects were female $88.6 \%$, and $37.4 \%$ had no children. In terms of educational status $86.2 \%$ were university graduates, in terms of employment type in hospital $30.1 \%$ were contractual, and in terms of work shift, $83.7 \%$ had rotating shift, the majority were working in ICU $24.4 \%$, then $17.1 \%$ in wards, and $9.8 \%$ in emergency departments. The results showed that mean of marital satisfaction total score was $27.85 \pm 169.97$ that $0.8 \%$ had severe dissatisfaction with marital life, $19.5 \%$ had dissatisfaction with marital life, $63.4 \%$ had relative satisfaction with marital life, $14.6 \%$ had high satisfaction with marital life, and $1.6 \%$ had great satisfaction with it. The highest mean of areas in nurses'

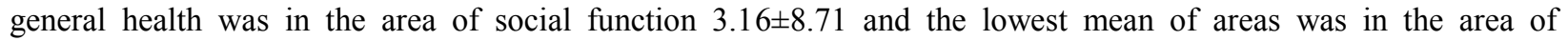
depression $3.98 \pm 2.64$. Among the nurses $54.4 \%$ were healthy form general health point of view and $45.5 \%$ were patient. The mean of total job stress score was $17.20 \pm 81.96$. Among them $21.1 \%$ had low stress, $68.3 \%$ had moderate stress, and $10.6 \%$ had high stress. The results showed that there were significant relationships between age $(\mathrm{r}=0.192, \mathrm{p}=0.03)$ and work experience $(\mathrm{r}=0.22, \mathrm{p}=0.01)$, and age of spouse and the scope of financial management of marital satisfaction $(\mathrm{r}=0.241, \mathrm{p}=0.01)$. The results showed that there were no significant relationships between nurses' workplace and total marital satisfaction $(\mathrm{p}=0.61)$, total job stress $(\mathrm{p}=0.24)$, and total general health $(\mathrm{p}=0.25)$. Pearson's correlation coefficient showed there were no relationships between the areas of job stress, marital satisfaction, and general health $(\mathrm{p}>0.05)$ and there were significant relationships between the areas of general health except social function with marital satisfaction. Total score of marital satisfaction and nurses' general health $\mathrm{r}=0.435$ and the linear regression equation is: "Total score of marital satisfaction $=196.512-1.089$ ". Based on the above linear regression equation we expect for every unit increase in the total score of general health, 1.089 units of total score of marital satisfaction will be decreased. Table 1, based on multiple regression analysis between general health areas with marital satisfaction, showed there was a significant relationship between depression and anxiety with marital satisfaction and the regression equation is: "Total marital satisfaction $=188.464-2.144$ (anxiety) -1.0698 (depression)". The results of Table 2 showed that there was a significant relationship between only total marital satisfaction with total general health $(\mathrm{p}<0.0001)$. There was no significant relationship between job stress and total general health $(\mathrm{p}=0.893)$ and between total job stress and total marital satisfaction $(\mathrm{p}=0.319)$. 
http://www.ephysician.ir

Table 1. Regression between General Health domains and Marital Satisfaction

\begin{tabular}{|c|c|c|c|c|c|c|c|}
\hline \multirow[t]{2}{*}{ Model } & \multicolumn{2}{|c|}{$\begin{array}{l}\text { Unstandardized } \\
\text { Coefficients }\end{array}$} & $\begin{array}{l}\text { Standardized } \\
\text { Coefficients }\end{array}$ & \multirow[t]{2}{*}{$\mathrm{t}$} & \multirow[t]{2}{*}{ Sig } & \multicolumn{2}{|c|}{ 95\% Confidence Interval for B } \\
\hline & $\mathrm{B}$ & Std. Error & Beta & & & Lower Bound & Upper Bound \\
\hline Constant & 188.464 & 4.005 & & 47.108 & 0.0001 & 180.717 & 196.575 \\
\hline Anxiety & -2.144 & 0.612 & -0.335 & -3.503 & 0.001 & -3.356 & -0.932 \\
\hline Depression & -1.698 & 0.668 & -0.243 & -2.543 & 0.012 & -3.021 & -0.376 \\
\hline
\end{tabular}

Table 2. Relationship between Job Stress, Marital Satisfaction and General Health Nurses

\begin{tabular}{|l|l|l|l|l|}
\hline & & $\begin{array}{l}\text { Total. Marital } \\
\text { Satisfaction }\end{array}$ & $\begin{array}{l}\text { Total. Job } \\
\text { stress }\end{array}$ & $\begin{array}{l}\text { Total. General } \\
\text { health }\end{array}$ \\
\hline \multirow{3}{*}{$\begin{array}{l}\text { Total. Marital } \\
\text { Satisfaction }\end{array}$} & $\begin{array}{l}\text { Pearson } \\
\text { Correlation }\end{array}$ & 1 & 0.091 & $-0.435^{*}$ \\
\cline { 2 - 5 } & Sig. (2-tailed) & & 0.319 & 0.000 \\
\cline { 2 - 5 } & $\mathrm{n}$ & & 123 & 123 \\
\hline \multirow{5}{*}{ Total. Job stress } & $\begin{array}{l}\text { Pearson } \\
\text { Correlation }\end{array}$ & & 1 & 0.012 \\
\cline { 2 - 5 } & Sig. (2-tailed) & & 123 & 123 \\
\cline { 2 - 5 } & $\mathrm{n}$ & & & 1 \\
\hline \multirow{3}{*}{ Total. General Health } & $\begin{array}{l}\text { Pearson } \\
\text { Correlation }\end{array}$ & & & 123 \\
\cline { 2 - 5 } & Sig. (2-tailed) & & & 1293 \\
\cline { 2 - 5 } & $\mathrm{n}$ & & & \\
\hline
\end{tabular}

* Correlation is significant at the 0.01 level (2-tailed).

\section{Discussion}

This study aimed to determine the amount of marital satisfaction and its relationship with job stress and general health among nurses working in teaching hospitals of Qazvin. The results showed that the majority of nurses had relative marital satisfaction that was consistent with the study of Banaian (32), Zandipour et al. (34) Askarian Omran et al. (35) but in the study of Rajabi et al., the majority of employees had marital satisfaction of more than average (29). The results of the present study showed that $54.4 \%$ were healthy from a general health view and $45.5 \%$ were patient. The highest mean of areas in general health was in the social function area and the lowest was in the area of depression symptom, which was consistent with the study of Rahpeima, Banaian $(36,32)$. But in the study of Shahi et al. $47.5 \%$ of the subjects were healthy in terms of general health and $52.5 \%$ of them were patient, which was inconsistent with the present study (37). In the study of Noorian, $44.7 \%$ of nurses were healthy and $55.3 \%$ of them were patient, which was the highest mean in the social function area and the lowest mean in the depression area, (38) which was consistent with the present study. Having general health among nurses is important. Nurses need to have effective interpersonal communication and their constructive communication with other members of the health care team leading to professional solidarity and cohesion, is enhanced by psychological balance (18). The results indicated moderate stress in nurses which was consistent with the study of Molaie (2), Ghasemi (24) but in the study of Lee et al., (39) the majority of nurses had normal stress and the reason for the research results' inconsistency are factors affecting nurses' job stress and their mental condition when completing the questionnaire, and sociocultural factors prevailing in society which are not unexpected. In this study, it was found that by increasing age and work experiences of nurses, their marital satisfaction increased, but in the study of Askarian Omran et al., the relationships were significant and reverse (35), but in a real study there was no relationship (15). In the study of Malekiha and Asadzadeh, there was no significant relationship $(40,41)$ and the reasons of inconsistency of results were factors affecting marital satisfaction including nurses' psychological factors, workplace, length of marriage, and economic conditions. There were no significant relationships between the workplace of nurses with marital satisfaction, job stress, and general health, which was consistent with the study of Bahrami (42), but it was inconsistent with the study of Sui Yu Yau et al. (4). Based on the type of nurses' workplace in studies, differences in their results seem logical. The results of the current study, indicate a significant relationship between marital satisfactions with nurses' general health. Due to the fact that increase of scores in test of general health shows disorder in nurses' general health, so less score of general health in people will lead to more marital satisfaction, which was consistent with several studies $(43,36,44)$, but was inconsistent with the study of Shafiee Kandjani et al. investigating the correlation of psychopathology and women's marital satisfaction (45). It can be concluded that lack of general 
health reduces the likelihood of having satisfactory relationships and following that, reduces communication with family and society, thus expressing emotions to spouse will be less, and then leads to separation and dissolution of marriage. On the other hand, by reducing people's general health, effective communications with others, especially with spouse, will be changed and it has negative effect on spouse's behavior and consequently, on their marital satisfaction. In general, by increasing general health of nurses, their marital satisfaction will be increased and contrarily, mental pressure followed by marital problems, is an important factor in the creation of various physical and mental diseases.

In this study, there was no significant relationship between nurse's job stress and their general health, which was inconsistent with the study of Shahraki Vahed (18), Barzideh (6), and Navidian (20). In a study, Wang stated that job stress is an important factor in general health disorder (46). One of the characteristics of individuals resistant to stressful events is having general health. Researchers have pointed out many other factors affecting nurses' general health (18) that can be the reasons for this inconsistency. There was no significant relationship between job stress and marital satisfaction. In other words, by increasing nurses' job stress, their marital satisfaction had no change, which was inconsistent with other studies $(1,36,47)$. In these studies, there was a positive relationship between general health and marital satisfaction and it was expressed that by reducing general health, people will lose the chance of having a healthy relationship and also it leads to decrease in their relationships with others, especially with their spouse and as a result, expressing feelings and emotions will be less and lead to marital dissatisfaction. Of course, the reason of this inconsistency with the present study can be the effect of several factors (personal, psychological, and social) and the culture governing city and sampling method.

\section{Conclusions}

The findings showed that the majority of nurses were healthy from a general health view, had relative satisfaction with marital life, moderate stress, and by increasing general health score their marital satisfaction was decreased. The functional significance of these findings is that the damage to general health and thus reducing marital satisfaction will lead to a waste of money and productivity at work, and subsequently reduce it in a person's life. It is suggested to do further studies with larger sample sizes and comparisons between teaching hospitals with private hospitals. Conducting a complementary study on the effect of educational interventions on level of stress, mental health, and marital satisfaction can be the right direction for future research on this topic.

\section{Acknowledgments:}

This article was derived from approved research proposal, and sponsored by the University of Medical Sciences which hereby is acknowledged. We appreciate officials of teaching hospitals of the Medical Sciences University and nurses who have cooperated in collecting samples.

\section{Conflict of Interest:}

There is no conflict of interest to be declared.

\section{Authors' contributions:}

All authors contributed to this project and article equally. All authors read and approved the final manuscript.

\section{References:}

1) Peiman pak F, Mansur L, Sadeghi M, Purebrahim T. The Relationship of Job Stress with Marital Satisfaction and Mental Health in Nurses of Tehran Hospitals. Quarterly Journal of Career \& Organizational Counseling. 2013; 4(13): 27-54.

2) Molaie B, Mohamadi M, Habibi A, Zamanzadeh V, Dadkhah B, Molavi P, et al. A Study of Job Stress and Its Related Causes among Employed Women in Ardabil City. J Ardabil Univ Med Sci. 2011; 11(1): 76-85.

3) Nabirye RC, Brown KC, Pryor ER, Maples EH. Occupational stress, job satisfaction and job performance among hospital nurses in Kampala, Uganda. J Nurs Manag. 2011; 19(6): 760-8. doi: 10.1111/j.13652834.2011.01240.x. PMID: 21899629.

4) Yau SY, Xiao XY, Lee LY, Tsang AY, Wong SL, Wong KF. Job stress among nurses in China. Appl Nurs Res. 2012; 25(1): 60-4. doi: 10.1016/j.apnr.2011.07.001. PMID: 21855294.

5) Darvishi E, Sadeghi F, Saed Panah K. Evaluation of effective factors on occupational stress in firefighting personnel. Journal of Health System Research. 2015; 11(1): 184-92.

6) Barzideh M, Choobineh A, Tabatabaei S. Job stress dimensions and their relationship to general health status in nurses. Occupational Medicine Quarterly Journal. 2013; 4(3): 17-27. 
7) Gholam Nejad H, Nikpeyma N. Occupational stressors in nursing. Iran Occupational Health Journal. 2009; 6(1): 22-7.

8) Teimori F. Job stressors in nurses. Journal of faculty nurse Army of Republic Islamic Iran. 2011; 11(1): 325.

9) Al Hosis Kh F, Mersal FA, Keshk LI. Effects of Job Stress on Health of Saudi Nurses Working in Ministry of Health Hospitals in Qassim Region in KSA. Life Sci J. 2013; 10(1): 1036-44.

10) Mohammadi Sh, Maghsodi M. An Investigation of the Relationship between Jobs Stress and Marital Satisfaction among Females Personnel. Quarterly Journal of Career \& Organizational Counseling. 2012; 3(9): 74-87.

11) Attari U, Aman elahifard A, Mehrabifard M. The relationship between personality factors-individual, family and marital satisfaction in Ahvaz city government staff. Journal Psychology and Educational Sciences. 2006; 3(1): 81-108.

12) Mangeli M, Ramezani T, Mangeli S. The Effect of Educating about Common Changes in Pregnancy Period and the Way to Cope with them on Marital Satisfaction of Pregnant women. Iranian Journal of Medical Education. 2009; 8(2): 305-13.

13) Augusto Landa JM, López-Zafra E, Berrios Martos MP, Aguilar-Luzón Mdel C. The relationship between emotional intelligence, occupational stress and health in nurses: a questionnaire survey. Int J Nurs Stud. 2008; 45(6): 888-901. doi: 10.1016/j.ijnurstu.2007.03.005. PMID: 17509597.

14) Owusu Amponsah M. Workstress and marital relations. Educational Research. 2011; 1(2): 757-64.

15) Wagheiy $Y$, Miri M, Ghasemipour M. A survey about effective factors on the marital satisfaction in employees of two Birjand universities. Journal of Birjand University of Medical Sciences. 2009; 16(4): 43 50.

16) Schlick CM. Industrial Engineering and Ergonomics Visions, Concepts, Methods and Tools Festschrift in Honor of Professor Holger Luczak. Berlin, Springer. 2009.

17) Salvendy G, Karwowski W. Advances in Physical Ergonomics and Safety Kentucky USA. CRC Press. $2012 ; 560$.

18) Shahraki Vahed A, Mardani Hamuleh M, Sanchuli J, Hamedi sharaki S. Assessment of the relationship between mental health and job stress among nurses. Journal of Jahrom University of Medical Sciences. 2010; 8(3): 34-40.

19) Kopp MS, Stauder A, Purebl G, Janszky I, Skrabski A. Work stress and mental health in a changing society. Eur J Public Health. 2007; 18(3): 238-44. doi: 10.1093/eurpub/ckm077. PMID: 17686795.

20) Navidian A, Masudi Gh, Mosavi S. Study of occupational stressors and their relationship with Mental health nurses at the emergency hospital in Zahedan. Journal of Kermanshah University of Medical Sciences. 2005; 9(3): 517-26.

21) Banijamali Sh, Nafisi Ch, Yazdi SM. Root finding of family break up in relation to social psychological aspects of girls and boys before marriage. Journal of training Science and Psychology of Shahid Chamran University Ahwaz. 2004; 11(3): 143-70.

22) Shahraki Vahed A, Mardani Hamuleh M. Assessment of the relationship between mental health and job stress among nurses. The Journal of Marriage and Family. 2010; 8(3): 34-40.

23) Gray-Toft P, Anderson JG. The nursing stress scale: Development of an instrument. Journal of Psychopathology and Behavioral Assessment. 1981; 3(1): 11-23. doi: 10.1007/BF01321348.

24) Mortaghi Ghasemi M, Ghahremani Z, Vahedian Azimi A, Ghorbani F. Nurses Job Stress in Therapeutic Educational Centers in Zanjan. Journal of Research Development in Nursing \& Midwifery. 2011; 8(1): 4251.

25) Rezaee N, Behbahany N, Yarandy A, Hosseine F. Correlation between Occupational Stress and Social Support among Nurses. Iran Journal of Nursing. 2006; 19(46): 71-8.

26) Payami M. Survey the status of social support and its relationship with occupational burnout intensive unit. Thesis for the Master degree of Nursing. Tehran: Tarbiat Modares University of Medical Science. 1997.

27) Fowers BJ, Olson DH. Enrich Marital Inventory, A discriminant validity and cross-validity assessment. J Marital Fam Ther. 1989; 15(1): 65-79. doi: 10.1111/j.1752-0606.1989.tb00777.x. PMID: 21118433.

28) Saatchi M, Kamkari K, Asgarian M. Psychological tests. 1nd edition. Tehran: Publisher Edition. 2010; 20920.

29) Rajabi GR. Factorial Structure of Marital Satisfaction Scale in Married Staff Members of Shahid Chamran University. Journal of Psychiatry and Clinical Psychology. 2010; 15(4): 351-8.

30) Goldberg DP, Hillier VF. A scaled version of the General Health Questionnaire. Psychol Med. 1979; 9(1): 139-45. PMID: 424481. 
31) Molavi H. Validation factor structure and Reliability of the Farsi version of General Health Questionnaire 28 in Iranian students. Pakistan Journal of Psychological Research. 2002; 17(3-4): 87-98.

32) Banaian SH, Parvin N, Kazemian A. The Investigation of the Relationship Between Mental Health Condition and Martital Satisfaction. Scientific Journal of Hamadan Nursing \& Midwifery Faculty. 2006; 14(2): 52-62.

33) Barzideh M, Chobineh AR, Tabatabaee HR. Dimensions of job stress and its relationship to General health nurses. Occupational Medicine Quarterly Journal. 2012; 4(3): 17-27.

34) Zandipour T, Momeni Javid M. A Study on the Relationship between Marital Satisfaction and Job Satisfaction among Employees of Sewage Water Company in Tehran. Quarterly Journal of Career \& Organizational Counseling. 2011; 3(7): 113-29.

35) Askarian Omran S, Sheikholeslami F, Tabari R, Kazemnejhad leili E, Paryad E. Role of career factor on marital satisfaction of nurses. Holistic Nursing and Midwifery Journal. 2015; 25(4): 102-9.

36) Rahpeima N, Kazemi SA, Sohrabi N. The relationship between mental health and marital satisfaction and burnout among women in subordinate governors and governors in the province. Quarterly Journal of Women \& Society. 2012; 3(2): 161-37.

37) Shahi A, Ghaffari I, Ghasemi K. Relationship between mental health and marital satisfaction. Journal of Kermansha University of Medical Sciences. 2011; 15(2): 119-26.

38) Noorian C, Parvin N, Mehrabi T. Evaluation of the relationship between occupational stress and general health condition in nurses working in Isfahan university hospitals 2005. Journal of Nursing, Midwifery and Paramedical of Rafsanjan. 2010; 5(1 and 2): 45-52.

39) Lee I, Wong HH. Perceived occupational stress and related factors in public health nurses. J Nurs Res. 2002; 10(4): 253-60. PMID: 12522738.

40) Malekiha M, Baghban I, Fatehizade M. Study of effect shiftwork on work-family conflict and marital satisfaction in female nurses of educational hospital. Journal of Behavioral Sciences. 2008; 2(3): 253-62.

41) Asadzade M, Ebrahimi H, Mokhtarzadeh SH. Compare the marital satisfaction of nurses constant and rotating shifts working in hospitals Hospitals and clinics in Social Security Tabriz city. Nursing of caring Sciences. 2010; 20: 52-8.

42) Bahrami A, Akbari H, Mousavi GA, Hannani M, Ramezani Y. Job stress among the nursing staff of Kashan hospitals. Feyz. 2011; 15(4): 366-73.

43) Anagnostopoulos F, Niakas D. Job Burnout, Health-Related Quality of Life, And Sickness Absence In Greek Health Professionals. European Psychologist. 2010; 15(2): 132-41. doi: 10.1027/10169040/a000013.

44) Chambless DL, Fauerbach JA, Floyd FJ, Wilson KA, Remen AL, Renneberg B. Marital interaction of agoraphobic women: a controlled, behavioral observation study. Journal of Abnormal Psychology. 2002; 111(3): 502-12. doi: 10.1037/0021-843X.111.3.502. PMID: 12150426.

45) Shafee Kandejani A, Azar M, Janbozoorgi M, Noohi S, Hoseini SR. Investigation of correlation between psychopathology and marital satisfaction. Pajohande. 2006; 12(6): 483-90.

46) Wang W, Kong AM, Chair YS. Relationship between job stress level and coping strategies used by Hong Kong nurses working in an acute surgical unit. Appl Nurs Res. 2009; 24(4): 238-43. doi: 10.1016/j.apnr. 2009.09.003. PMID: 20974076.

47) Adib-Hajbaghery M, Lotfi MS, Hosseini FS. The Relationship between Occupational Stress and Marital Satisfaction of Nurses. Journal of Health and Care. 2014; 16(1): 9-18. 